\title{
Workshop Programme
}

Workshop I: Comprehensive Care Programme for Haemophiliacs

Introduction: Questions Regarding

Comprehensive Care: A Haemophiliac

Concerns

TheHaematologic/Orthopedic/Physiatric

Team Effort

The Role of the Nurse Coordinator

The Integration of Psychosocial Services -

A Realist Perspective

Outreach and Referral Aspects of a

Haemophilia Center - A Network of Care

Laboratory Aspects and Data Collection in

Haemophilia Care

Supervised Self-Treatment

Can a System of Comprehensive

Haemophilia Care be Legislated or

Supported?

Questions by a Haemophiliac

D.E.Colburn

H.H.Brackmann

T. Holbrook, C. C. Mintzer E.Wincott

C.J.Cornell

Y. Laurian, T. Lambert, M. Dreyfus

L. Sjamsoedin-Visser

M. McPherson, P. H. Levine and the US

Haemophilia Center Directors Consortium

W.Altendorf

Questions and Answers

Workshop II: Mobilizing Support for Haemophilia Care

Introduction A. F.H.Britten

Maintaining the Plasma Supply and Plasma Fractionation

An Overview on Plasma Production A. Josephson

Workshop Programme

15

Self-Sufficiency for Plasma in Belgium Harmonization of Quality Control and Product Licensing Procedure in Europe

Financing the Cost of Haemophilia Treatment

The Cost of Haemophilia Treatment and the 
Cost of the Lack of Treatment

Financing the Cost of Concentrates - The

United States Experience

How to Get Started - The Costa Rica

Experience

How to Get Started - Success in the Third

World

C. Vermylen D.Poggiolini

F. Etzel

L.Aledort

R.Cordero

P. M. Mannucci

Questions and Answers

Workshop III: National Haemophilia Societies and WFH

Introduction R.George

Haemophiliacs Expectation of Haemophilia C. Smit

Organizations

The National Organizations M. H. Maurer

The World Federation of HemophiliaF. Schnabel

Research in Haemophilia M. J. Larrieu

Care-Oriented Data Systems P. Jones

WFH Information Clearing House K. Schimpf

The Role of a National Society in S. Resnik

Haemophilia Education

World Haemophilia Youth M. G. Maynard

Financial Support - Funding of the New T. Goodwin

Zealand Haemophilia Society

Questions and Answers 